\title{
Analysis and Treatment of Water Contaminated by Petroleum Products
}

\author{
Nandini M.Naik ${ }^{\mathrm{a}}$, Girish S.Kulkarni ${ }^{\mathrm{b}}$, K.B.Prakash ${ }^{\mathrm{c}}$ \\ ${ }^{a}$ Associate Prof. Chemical Engineering Department K.L.E DR M.S.Sheshagiri College of Engineering \& \\ Technology, Udyambag,Belgaum-590008.Karnataka. \\ ${ }^{b}$ Professor, Environmental Science and Technology and Director Shivaji University Kolhapur, Maharashtra. \\ ${ }^{c}$ Professor, Civil Engineering Department and Principal of Govt. Engineering College Haveri. Karnataka.
}

\begin{abstract}
The unparalleled rate in population explosion and advancements in technology has created alarming impacts on the society. This has urged the need for vigilant and efficient data mining of these phenomena. Petroleum being an indispensible part of life has escorted to several detrimental results. Air and water are the major elements which fall prey to this. The present study involves rigorous scrutinizing with statistical analysis of test data carried out on water samples collected from petrol pumps and automobile service stations for the determination of nature of configuration. The samples were collected at regular time intervals and at the fixed place irrespective of the weather and climatic conditions that prevailed. The haphazardness or fuzziness of the amount of contamination present in water recipients due to petroleum products is being evaluated using regression analysis and the runs test. It is found that organic and inorganic chemicals are more in the collected sample that leads to chemical oxygen demand (COD) and the same was reduced using activated rice husk as an adsorbent. A case study involving its harmful effects on concrete is accessed via Scanning Electron Microscope (SEM) tests.
\end{abstract}

Index Terms: COD, regression analysis, runs test, SEM, adsorption.

(C) 2014 Published by MECS Publisher. Selection and/or peer review under responsibility of the Research Association of Modern Education and Computer Science.

\section{Introduction}

Water pollution and the factors that are associated with the same are the root causes of many harmful diseases both in the developed and developing nations [1]. Water pollution problems are pigeonholed by an assortment of intervening arbitrary pollution aspects like oil spills, chemical effluents, etc. Petroleum

* Corresponding author. Tel.:

E-mail address: mirzaie@nit.ac.ir 
contaminated water cannot serve any purpose owing to its carcinogenicity and heavy metal which are naturally available in ground water, can neither be destroyed nor be degraded. These contaminants enter our body through food, water and air. [2, 3, 4, 5]. Its adverse effects like asthma, malignancy, dizziness, etc., are predestined as in [6]. Even dye contaminated water leads to severe health conditions [7]. During oil transportation, accidently if its leakage occurs, it results in percolation in the soil and when this surpasses a certain threshold, the oil penetrates into ground water. Nevertheless, most of the volatile components evaporate; the foremost appalling traces get dissolved in groundwater. Protracted surveillance shows percolation in cement tanks used for petroleum products storage. A substitute for this is steel tanks which get corroded in due course of time. The familiar sources where this phenomenon is anticipated is,

- Leaks in piping and joints due to loose fitting of flanges and joints in the pipelines of transportation of petroleum products.

- Leakages in corroded tanks due to large time storage of petroleum products. This is due to its immense corrosive degree.

- A range of equipment breakdown in newly installed storage systems.

- Overfills and spills while filling tanks.

As a consequence, the elements of the environment affected by this are soil, groundwater, surface water and air. The current study is based on assessing the measure of the effluents present in the ground water and determining the randomness in the pollution which is indicative of the second law of thermodynamics and minimizing it using adsorption techniques. The effect of petroleum contaminated water on concrete is also briefed.

The paper is organized as follows, section II deals with the related work done in regard to the topic under discussion. The materials and methods used for this study are given in Section III. The section also deals with the adsorption study details. Results and discussions are given in Section IV. The paper is concluded in Section $\mathrm{V}$ and the future scope of the study is given in Section VI.

\section{Related Work}

In case of a catchment, Langrangian stochastic advective-reactive modeling can be used to assess the uncertainty and risk inherent in water pollution [8]. An applied methodology on River Tungabhadra of South India for overcoming the uncertainty in a fuzzy optimization model is developed as in [9], Chebyshev's inequality and statistical moments are used in other similar context [10]. The uncertainties are a consequence of pollutant attenuation and transport, pollutant emission, etc. [11] or due to randomness associated with various inputs, water quality simulation model being used, fuzziness or imprecision associated with pollution control agencies [12].

As per a survey, made in Belgaum, Karnataka (India); there are many published papers available on the impact assessment of water. As per a case study of Belgaum city, it is found that Chloride concentration is more in ground water [13]. It is also noticed that there is considerable increase in Chloride concentration as revealed by $[14,15,16,17,18]$.

\section{Materials and Methods}

50 sets of water samples were collected from various places nearer to Petrol pumps, garages, etc., from Belgaum -Khanapur regions during February 2011 to 2013 at an interval of 6 months respectively, in polythene bottles. 
Chemicals used in the experimental work for the impact assessment included, buffer solution of $\mathrm{pH} 0.4,0.1 \mathrm{~N}$ of Potassium chloride $(\mathrm{KCl})$ solution, Phenolphthalein indicator, Methyl orange indicator, $0.1 \mathrm{~N}$ of Sodium thiosulfate $\left(\mathrm{Na}_{2} \mathrm{~S}_{2} \mathrm{O}_{3}\right) .0 .25 \mathrm{~N}$ of Potassium dichromate $\left(\mathrm{K}_{2} \mathrm{Cr}_{2} \mathrm{O}_{7}\right), 0.25 \mathrm{~N}$ of Ferrous ammonium sulphate, Ferroin indicator, $1 \mathrm{~N}$ Mercuric sulphate, Sulphuric acid, $1 \mathrm{~N}$ of Sodium hydroxide, $0.5 \mathrm{~N}$ of Sodium hydroxide.

The $\mathrm{pH}$ is measured in the field by using portable battery operated $\mathrm{pH}$ meter (ELICO), and other parameters were determined in a laboratory using standard procedure given by [19]. Total dissolved solids (TDS) and electric conductivity (EC) were measured by TDS Conductivity meter (NAINA, NPC 361 D), Total hardness $(\mathrm{TH})$, Calcium $(\mathrm{Ca})$, Magnesium $(\mathrm{Mg})$, and Alkalinity, and chemical oxygen demand (COD) were analyzed by volumetric method.

Impact assessment of petroleum products contaminated water includes tests like $\mathrm{pH}$, alkalinity, electrical conductivity (EC), total dissolved solids, total hardness, calcium hardness, magnesium hardness and Chemical Oxygen Demand (COD). COD depends on organic and inorganic matters. The latter is suppressed for rendering less intricacy. COD is computed by taking into account the $\mathrm{pH}$, dosage, particle size of the adsorbent to reduce the maximum COD value, and the time period. Adsorption is carried out by using low cost adsorbent such as activated rice husk (ARH). The investigation covered 50 samples procured from diverse sections nearby to garages, petrol pumps, automobile service stations, and other places where the probability of oil spillage was high; in different spans of the year.

Water samples from different locations were collected at time intervals of 6 months for 2 years and the above mentioned tests were conducted.

A. Overall water impact assessment and the data mining schema technique can be assimilated through the following algorithm.

Input: 50 sets of water samples were collected in two years for 4 times from the same place.

Output: Building statistical models for the data.

\section{Conduct the 8 tests on water samples in the order,}

1. TDS (ppm), 2. EC ( $\mu$ ohms),

3. Alkalinity (mg/litre), 4. $\mathrm{pH}, 5$. Total hardness (mg/litre), 6. Calcium hardness (mg/litre),

7. Magnesium hardness ( $\mathrm{mg} / \mathrm{litre}), 8 . \mathrm{COD}$ ( $\mathrm{mg} / \mathrm{litre})$.

$\mathrm{n} \leftarrow 50 / /$ total number of samples

t๘test number

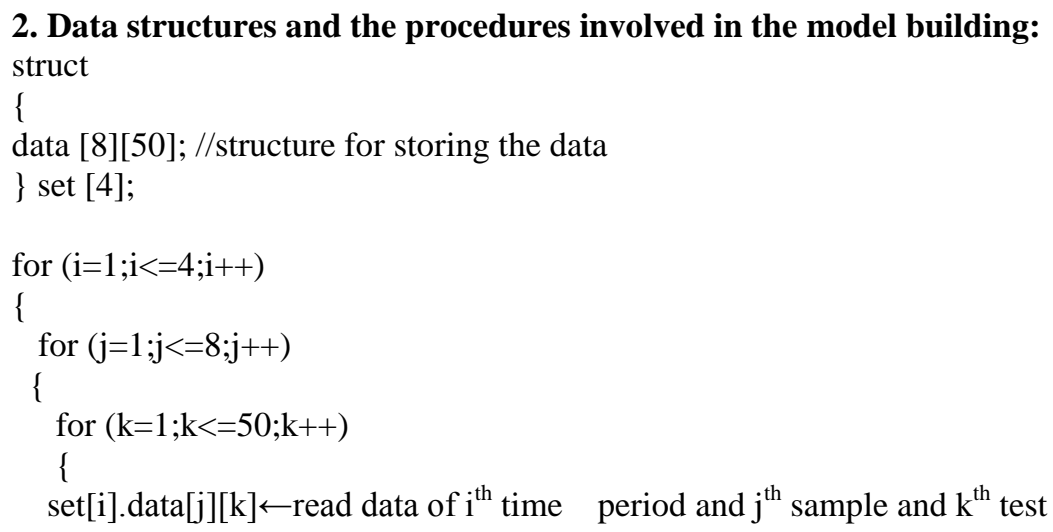




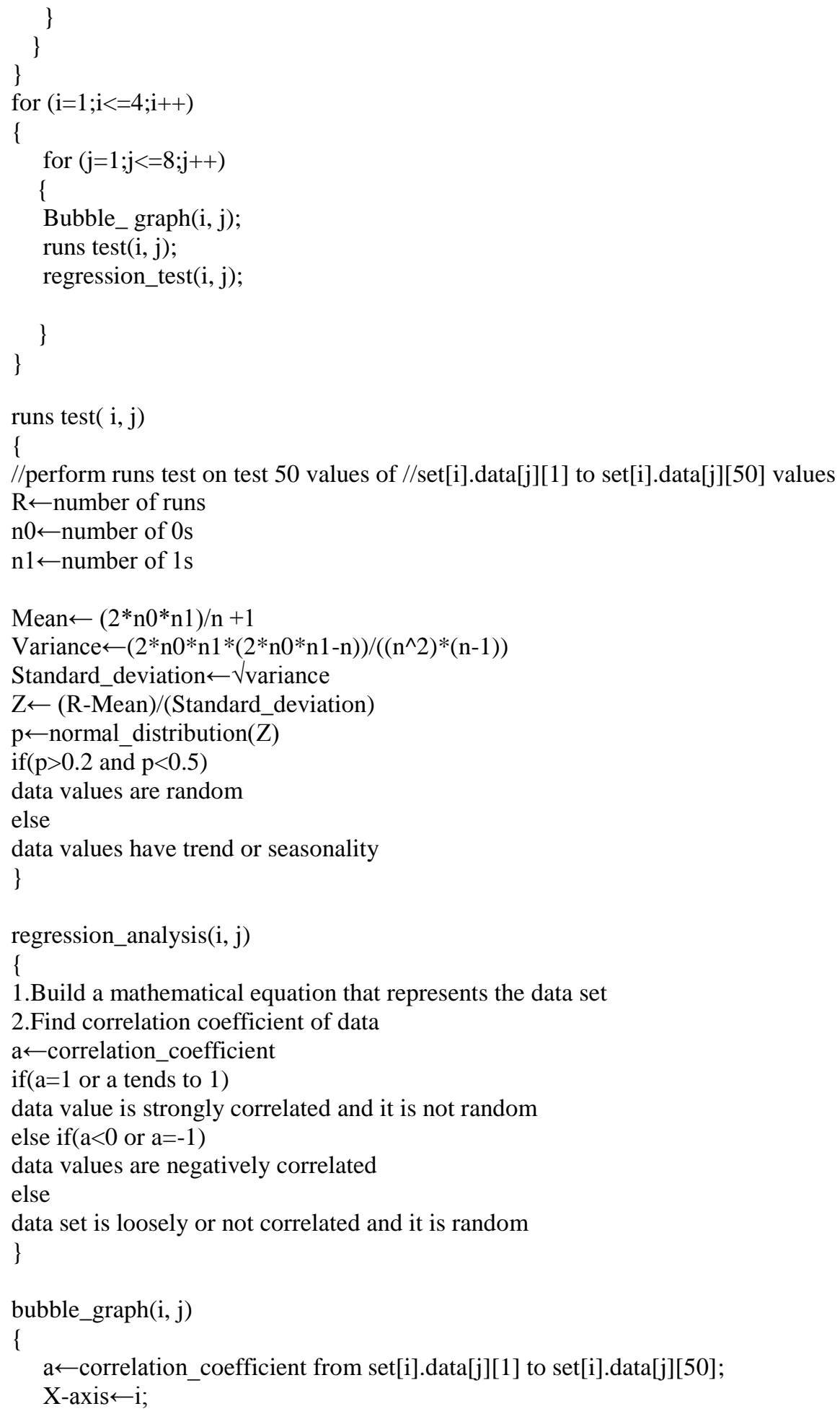


$\mathrm{Y}-$ axis $\leftarrow \mathrm{j}$;

$\mathrm{Z}$-axis(radii of bubble) $\leftarrow \mathrm{a}$;

Plot Bubble graph with the above parameters as co-ordinates

\}

3. Draw conclusions based on the obtained statistical results.

4. End.

B. Adsorption study

Adsorption study focuses on COD removal by using activated rice husk (ARH). Removal of COD can be made by using activated rice husk, carbon, coconut shell carbon and coconut fiber carbon at different temperatures [20,21, and 22]. Adsorption is diffusion or the movement of a given fluid constituent on a solid surface. Current study avails this by using rice husk activation technique [23] and adsorption is done with reference to parameters like effect of $\mathrm{pH}$, effect of contact time, effect of particle size and dosage.

\section{1) Effect of contact time:}

$200 \mathrm{ml}$ of 50 samples is taken in a flask and 0.2 gram of activated rice husk is added and then shaken in a laboratory shaker. For every 10 minutes, $20 \mathrm{ml}$ sample is collected till the last volume of the solution. In this study, the sample is shaken for 90 minutes (because after this, the COD values remain the same.); filtered using filter paper folding in funnel, then the filtrate is stored in a bottle. Finally the COD of each sample is obtained.

Fig. 3 shows the plot of the effect of time on the COD values. From the results, it was found that the COD values are inversely proportional to time and then a constant value is obtained called as the saturation time at which there is no change in COD. It is because of completion of the capacity of the adsorbent. Hence 70 minutes of contact time is selected.

\section{2) Effect of pH:}

$100 \mathrm{ml}$ of samples are taken. For each separate sample, $\mathrm{pH}$ of 2, 4, 10 and 12 is maintained. Then 0.1 gram of activated rice husk as adsorbent is added to each of 50 samples. All the samples were shaken by knowing the saturated time. 70 minutes was obtained as the saturated time, hence the sample is shaken for 70 minutes. After shaking, all the 50 samples are filtered separately and then the COD of each sample at pH 2, 4, 10 and 12 is calculated.

The implementation of the above test is shown in Fig. 2. The minimum COD obtained is $50 \mathrm{ppm}$ at $\mathrm{pH} 2.0$. Hence for the next analysis, 70 minutes of contact time and $\mathrm{pH}$ of 2.0 is selected.

\section{3) Effect of particle size:}

$100 \mathrm{ml}$ of sample is taken in a bottle. $\mathrm{pH}$ of solution (already calculated at minimum COD value) is maintained. Adsorbent of three different particle sizes are taken, 212 micrometers, 425 micrometers and 500 micrometers. 50 sample bottles of $100 \mathrm{ml}$ at $\mathrm{pH} 2.0$ (according to the above analysis, $\mathrm{pH} 2.0$ is obtained) is taken and 0.1 gram of activated rice husk of 50 respective particle size is added to the respective bottles. It is then shaken in laboratory shaker for 70 minutes, and then filtered and through the filtrates, COD is found.

The above test results are shown in Fig. 4. It is clear that, the COD value is minimal for average particle size of 212 micrometer. This is because, as particle size decreases, surface area for adsorption increases. For the next analysis, 212 micrometer particle size of adsorbent, 70 minutes of contact time (adsorption time) at $\mathrm{pH} 2.0$ is selected.

\section{4) Effect of Dosage:}


After finding the time, $\mathrm{pH}$ and particle size, the parameters are kept constant at minimum COD, hence at 70 minutes, pH 2.0, 212 micrometer average particle size, minimum COD is obtained. $100 \mathrm{ml}$ of sample is taken; activated rice husk is added at various dosages (grams) to the sample. Then the sample is shaken at maintained $\mathrm{pH}$ and average particle size. Then it is filtered and COD of filtrate was found at various dosages.

At minimum COD, the dosage is taken as saturated dosage. In this case, 0.1 grams $/ 100 \mathrm{ml}$ of sample solution are saturated dosage. The graphical analysis of this test is depicted in Fig. 5. It is clear that at optimum dosage is $0.1 \mathrm{~g} / 100 \mathrm{ml}$ sample solution.

\section{Case study}

\section{Assessing of the adverse effect of petroleum contaminated water on concrete:}

After regression analysis and treatment of the petroleum products contaminated water data samples, the study focuses on the impact of petroleum products on fly ash mixed concrete. An experiment carried out on petroleum products soaked fly ash mixed concrete and strength properties were tested. As well as tests like SEM, XRD on the petroleum products soaked fly ash mixed concrete were conducted and compared with the normal fly ash mixed concrete under sophisticated laboratory conditions. This was done to throw light on the hazardous impact petroleum products have on concrete.

\section{Results and Discussions}

As mentioned in the algorithm (Section 3.1), the runs test, regression analysis test, and bubble graph analysis was conducted for all the 4 data templates. Table 1 comprises of the $p$-value and the number of runs in the runstest, correlation values, and the regression models for the $1^{\text {st }}$ data set. Runs test is used to determine the degree of randomness in a given data sample. The test returns a value $\mathrm{p}$ which should be greater than 0.2 and lesser than 0.5 for the data to be random. Also the number of runs in each case should not be too large or too small with respect to the number of data values. Regression analysis involves finding the mathematical equation which represents the data series. For the equation to hold good, the correlation coefficient values should be 1 or should tend towards 1 . In such a case, there exists a trend or seasonality in the data set and the samples cannot be random. These two tests check for independence in the data sets.

In each case, it is evident from the statistical tools that nature of water contamination is chaotic in nature, i.e. it is not fixed (which is the cause of concern).

Fig.1 shows a bubble graph with the $\mathrm{X}$ axis depicting span of six months from February 2011 to 2013, Y axis indicates the 8 tests conducted in the following order:- 1 -TDS (ppm), 2-EC ( $\mu$ ohms), 3-Alkalinity (mg/litre), 4-pH, 5-Total hardness (mg/litre), 6-Calcium hardness (mg/litre), 7-Magnesium hardness (mg/litre), 8-COD. The radii of the bubbles indicate the correlation coefficients of the data sets taken in a particular test over 50 samples. Careful visualization of the radii of the bubbles along the horizontal axis shows the variation or the randomness inherent in water pollution. A prototype model to study the harmful effects of petroleum products is conducted using the SEM test as shown in Fig. 6a and 6b. In Fig. 6a, we can see the presence of globular structure of concrete mixed fly ash, which is evident of strong, cohesive forces which tightly bind the molecules and increase the durability. After immersing the same specimens into petroleum products for 3 months, the globular structure of molecules is lost, which is indicative of the degrading effect due to petroleum products. This increases the porosity and culminates into degradation. The destruction of cohesive forces takes place in the former case, whereas the addition of fly ash enhances the durability in the latter case.

To reduce this harmful effect, adsorption techniques were employed on the water samples and the COD was considerably reduced. This is evident from Fig. 2 through 5. 


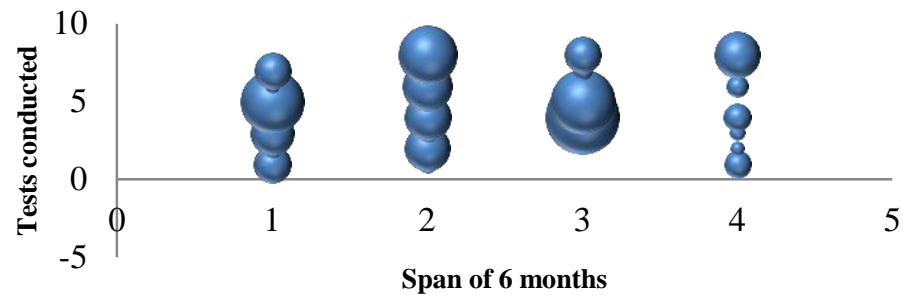

Fig. 1. Correlation between the tests and year.

Table 1. Statistical test analysis conducted on the data sets.

\begin{tabular}{lcccc}
\hline \multicolumn{1}{c}{ Name of the test } & Number of runs & $\mathbf{p}$-value in runs test & Regression analysis & Co-relation value \\
\hline & & & & \\
1.TDS & 24 & 0.298305 & $\mathrm{y}=-1.373 \mathrm{x}+293.4$ & 0.025 \\
2.EC & 24 & $1.60863 \mathrm{E}-17$ & $\mathrm{y}=1.399 \mathrm{x}+423.9$ & 0.007 \\
3.Alkalinity & 25 & 0.4045 & $\mathrm{y}=-0.149 \mathrm{x}+33.11$ & 0.034 \\
4.pH & 21 & 0.089187807 & $\mathrm{y}=-0.000 \mathrm{x}+5.855$ & 0 \\
5.Total hardness & 28 & $1.51083 \mathrm{E}-13$ & $\mathrm{y}=0.940 \mathrm{x}+91.95$ & 0.072 \\
6.Calcium hardness & 30 & 0.896985973 & $\mathrm{y}=-0.173 \mathrm{x}+97.03$ & 0.003 \\
7.Magnesium hardness & 22 & 0.134669064 & $\mathrm{y}=-0.091 \mathrm{x}+27.08$ & 0.024 \\
8.COD & 23 & 0.19563364 & $\mathrm{y}=0.086 \mathrm{x}+193.1$ & 0 \\
\hline
\end{tabular}

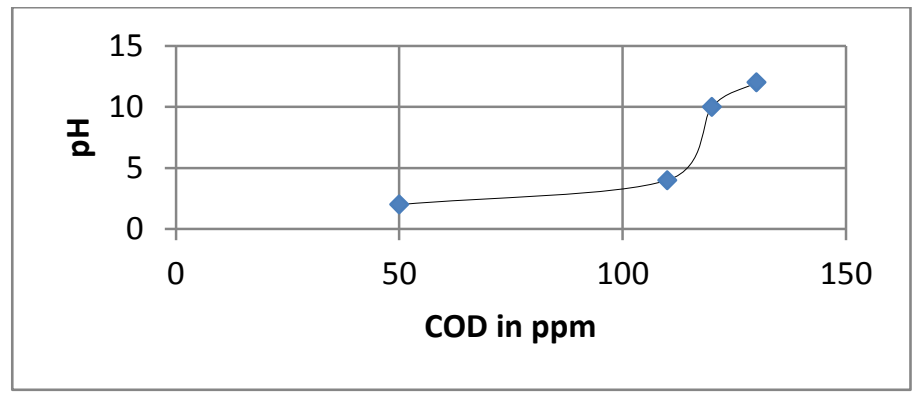

Fig. 2. Relation between the COD and $\mathrm{pH}$ values.

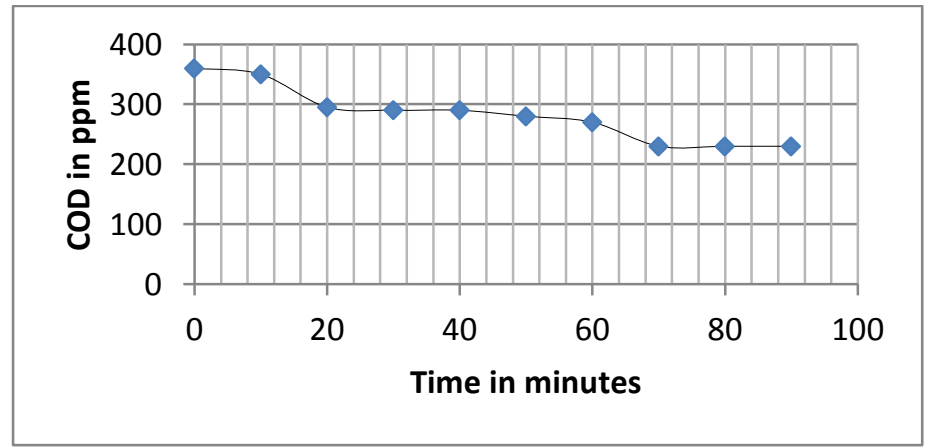

Fig. 3. Variation of COD with respect to time. 


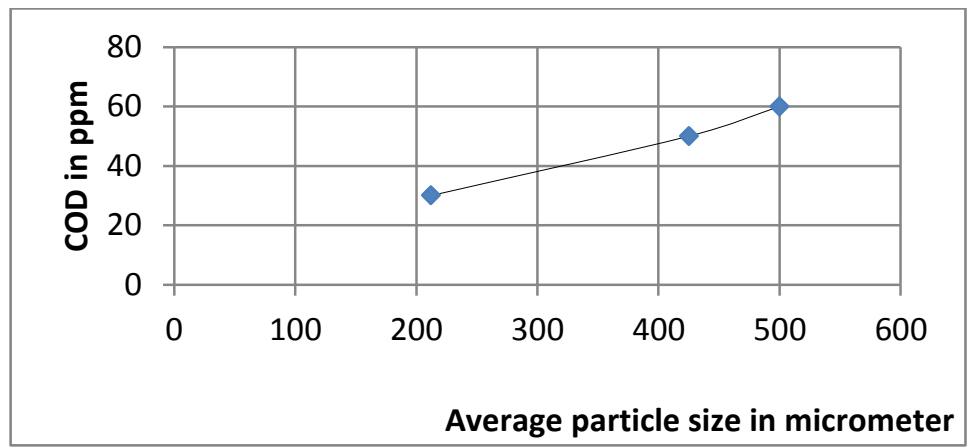

Fig. 4. Effect of particle size on COD.

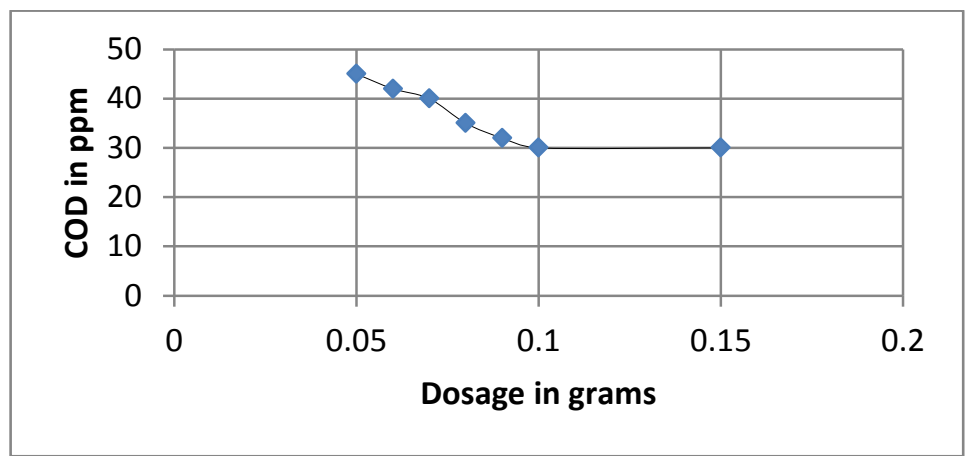

Fig. 5. Impact of activated rice husk dosage on COD.
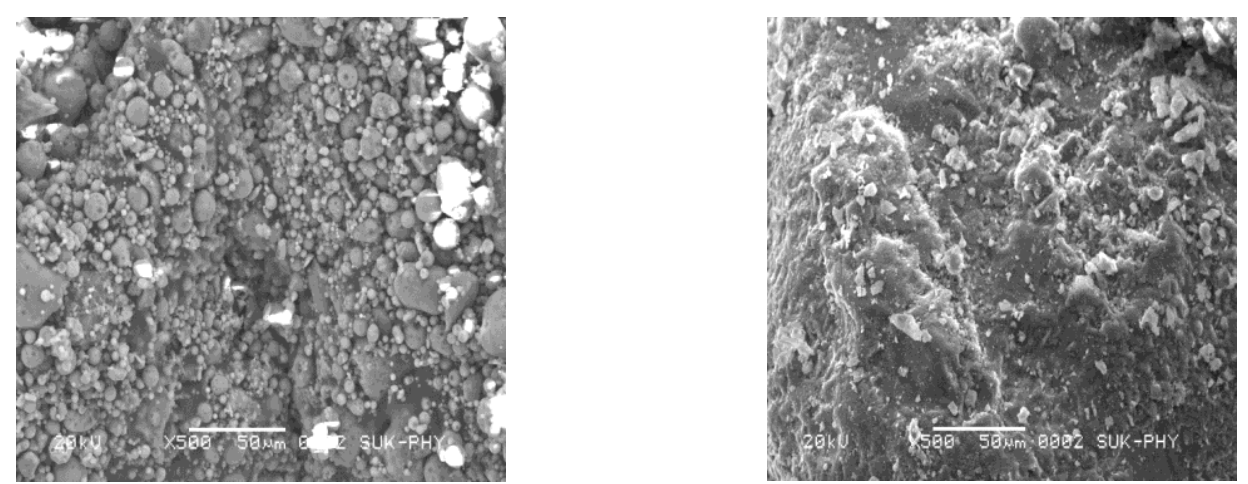

Fig. 6a and 6b: Morphology of fly ash mixed concrete subjected to scanning electron microscope (SEM) and morphology of fly ash mixed used engine oil soaked concrete subjected to scanning electron microscope (SEM).

\section{Conclusions}

As a summary, the paper focuses on the presence of petroleum products in local water bodies which remain unnoticed and culminates in water pollution. The magnitude of pollution has been studied by subjecting the 
samples to 8 chemical tests. The values returned by the tests are scrutinized exhaustively with the aid of statistical tools and the erratic behavior of water pollution through petroleum products is determined. By using activated rice husk as an adsorbent the contaminated water is treated and their COD is reduced. The case study to highlight the effects of petroleum products on concrete was also done.

\section{Future Scope}

The results obtained from the study can be used to design efficient pollution control schemas. Timely monitoring of the degree of pollution is important and can be done in the fashion similar to the one deployed in this study. The case study showing the degrading effect on concrete due to petroleum products creates an urge to take necessary measures to overcome it.

\section{Acknowledgements}

The authors are indebted to KLE Dr. M. S. Sheshagiri College of Engineering and Technology, Belgaum, and Shivaji University, Kolhapur; for all the crucial amenities provided for the experimentation.

\section{References}

[1] Adebayo P. Idowu., et al " Development of a Web Based Environmental Health Tracking System for Nigeria" I.J. Information Technology and Computer Science, 2012, 7, 61-71 Published Online July 2012 in MECS. DOI: 0.5815/ijitcs.2012.07.08.

[2] Sun Ying., "The Utilization of Escherichia Coli-based Magnetic Nanobeads as An Ultrasensitive Biosensor for Mercucy, I.J. Engineering and Manufacturing 2011, 3, 50-54, MECS. DOI: 10.5815/ijem.2011.03.08.

[3] H. Abu Qdaisa and H. Moussab, "Removal of heavy metals from wastewater by membrane processes: a comparative study," Desalination. USA, vol. 164, 2004, pp. 105-110.

[4] W.C. Leung, M.F. Wong, H. Chua, W. Lo and C.K. Leung, "Removal and recovery of heavy metals by bacteria isolated from activated sludge treating industrial effluents and municipal wastewater," Water Sci. Technol. Eng., vol. 41, (2000), pp. 233-240.

[5] Zhang, Xiaodong, Guo H. Huang, Qianguo Lin, and Hui Yu. "Petroleum contaminated groundwater remediation systems design: A data envelopment analysis based approach." Expert Systems with Applications 36, no. 3 (2009):5666-5672.Elsevier, DOI: 0.1016/j.eswa.2008.06.136.

[6] Lopez et al, "Human health risks of petroleum-contaminated groundwater", Spain.

[7] Crini, Gregorio. "Non-conventional low-cost adsorbents for dye removal: a review." Bioresource technology 97, no. 9 (2006): 1061-1085. Elsevier. DOI:10.1016/j.biortech.2005.05.001.

[8] Klas Persson, Georgia Destouni, "Propagation of water pollution uncertainty and risk from the subsurface to the surface water system of a catchment", Journal of Hydrology 377 (2009) 434-444, Elsevier. DOI: 10.1016/j.jhydrol.2009.09.001.

[9] Subinal Ghosh and P.P. Mujumdar, "A Fuzzy Waste Load Allocation Model Integrating Skewness of Distributions".

[10] Subimal Ghosh, P.P.Mujumdar, "Minimization of constraint violation in fuzzy multi objective programming", 7th International Conference on Hydro informatics, HIC 2006, Nice, France, 7th International Conference on Hydro informatics.

[11] Christian Baresal, "Environmental management of water systems under uncertainty", Doctoral Thesis, Stockholm, Sweden 2007.

[12] V.R. Subbarao Vemula, P.P. Mujumdar, Subimal Ghosh,"Risk evaluation in water quality management 
of a river system".

[13] Sameer V, Yamakanamardi et al, "Assessment of chloride concentration in groundwater: A case study for Belgaum City", International journal of environmental sciences, Volume 2, No 1, 2011.

[14] Piscopo, Antoine, Didier Robert, and Jean Victor Weber. "Influence of $\mathrm{pH}$ and chloride anion on the photo catalytic degradation of organic compounds: Part I. Effect on the benzamide and parahydroxybenzoic acid in TiO2 aqueous solution." Applied Catalysis B: Environmental 35, no. 2 (2001): 117-124. Elsevier. PII: S0926-3373(01)00244-2.

[15] Xagoraraki, I., and D. Kuo. "Water pollution: Emerging contaminants associated with drinking water." International Encyclopedia of Public Health 6 (2008): 539-550. Elsevier.

[16] Sarwade et al., (2008). "Assessment of groundwater quality in urban area, Belgaum city, Karnataka, India", Journal of Applied Geochemistry, 10(2), pp 148- 165.

[17] Camargo, Julio A., and Álvaro Alonso. "Ecological and toxicological effects of inorganic nitrogen pollution in aquatic ecosystems: a global assessment." Environment international 32, no. 6 (2006): 831 849. Elsevier. DOI:10.1016/j.envint.2006.05.002.

[18] Boyd, Claude E., and Laurence Massaut. "Risks associated with the use of chemicals in pond aquaculture." Aquacultural Engineering 20, no. 2 (1999): 113-132. Elsevier.

[19] APHA, "Standard methods for the examination of water and wastewater", American Public Health Association, Washington D.C, (1985). PII: S0144-8609(99)00010-2.

[20] Mohan, Dinesh, Kunwar P. Singh, and Vinod K. Singh. "Wastewater treatment using low cost activated carbons derived from agricultural byproducts - a case study." Journal of Hazardous materials 152, no. 3 (2008): 1045-1053. DOI: 10.1016/j.jhazmat.2007.07.079.

[21] Bhatnagar, Amit, Eva Kumar, and Mika Sillanpää. "Fluoride removal from water by adsorption-a review." Chemical Engineering Journal 171, no. 3 (2011): 811-840. Elsevier. DOI: 10.1016/j.cej.2011.05.02.

[22] Ali Hashem et al, "Bio adsorption of Cd (II) from Contaminated Water on Treated Sawdust: Adsorption Mechanism and Optimization" Journal of Water Resource and Protection, 2013, 5, 82-90. Doi:10.4236/jwarp.2013.51010.

[23] ADEMILUYI, F. T et al "Adsorption and Treatment of Organic Contaminants using Activated Carbon from Waste Nigerian Bamboo”. J. Appl. Sci. Environ. Manage. September, 2009 Vol. 13(3) 39 - 47.

\section{Author's Profile}

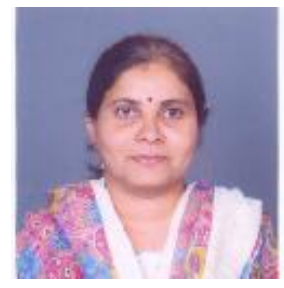

Prof. Nandini M Naik has graduated in Chemical Engineering from SIT, Tumkur and completed her post-graduation in Chemical Engineering from Shivaji University, Kolhapur. She is currently working as Associate Professor in Chemical Engineering Department, KLE DR. M.S.Shesagiri College of Engineering and Technology, Belgaum, Karnataka. She is having a teaching experience of 15 years, and is a research scholar in Environmental Science and Technology, Department of Technology, Shivaji University, Kolhapur.

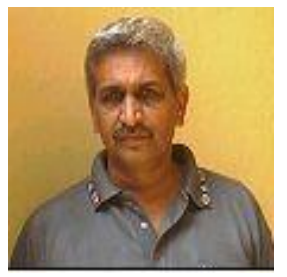

Girish.S.Kulkarni, has graduated in Civil Engineering and post graduated in Environmental Engineering from Shivaji University, Kolhapur and $\mathrm{Ph} . \mathrm{D}$ in Environmental Engineering and Technology from Walchand College of Engineering, Sangli. He is currently working as Professor in Environmental Science and Technology, Department of Technology, Shivaji University Kolhapur, Maharashtra. He has published and presented many technical papers in international and national conference. 


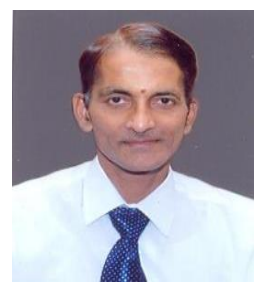

Dr. K. B. Prakash, has graduated in Civil Engineering from National Institute of Engineering Mysore and post graduated in Structural Engineering and $\mathrm{Ph}$. D degree from Walchand College of Engineering, Sangli. He is currently working as Professor and Head in Civil Engineering Department and Principal of Government Engineering College, Haveri, Karnataka. He has 27 years of teaching experience and 2 years of industrial experience. $\mathrm{He}$ has published around 200 technical papers in International/National Journals and proceedings of International/ National conferences.

How to cite this paper: Nandini M.Naik, Girish S.Kulkarni, K.B.Prakash,"Analysis and Treatment of Water Contaminated by Petroleum Products", IJEM, vol.4, no.5, pp.1-11, 2014.DOI: 10.5815/ijem.2014.05.01 